\title{
New Leakage Model for Naturally Fractured Formations Considering the Effects of Dual-System Hydro- Mechanical Coupling
}

\author{
Hao Peng $\left(\mathbb{D},{ }^{1}\right.$ Qian Li $\left(\mathbb{D},{ }^{1}\right.$ JiaJia Gao, ${ }^{1}$ Hu Yin, ${ }^{1}$ and Jun Wang ${ }^{2}$ \\ ${ }^{1}$ Petroleum Engineering School, Southwest Petroleum University, Chengdu, Sichuan 610500, China \\ ${ }^{2}$ Chuanqing Drilling Company Limited Chuanxi Drilling Company, Chengdu, Sichuan 610000, China \\ Correspondence should be addressed to Qian Li; liqianswpi@vip.sina.com
}

Received 15 October 2020; Revised 9 December 2020; Accepted 14 December 2020; Published 2 January 2021

Academic Editor: Yongcun Feng

Copyright $\odot 2021$ Hao Peng et al. This is an open access article distributed under the Creative Commons Attribution License, which permits unrestricted use, distribution, and reproduction in any medium, provided the original work is properly cited.

\begin{abstract}
Within the existing leakage model accounting for drilling mud loss in naturally-fractured formations, the leak-off velocity is assigned to a fixed value or described by the Cater model, which does not consider the influence of dual-system hydromechanical coupling effects between fracture-wall and fracture-inner systems. The dual-system between the formation and fracture is controlled by the flowing net pressure inside the fracture, which determines the dynamic width of the natural fracture and leak-off velocity. In this study, first, the leak-off velocity under the hydromechanical coupling of the fracture-wall system was obtained based on the coupled governing equations of the solid and liquid phases of the natural fracture-wall, as well as Darcy's law. Second, the leakage-front invasion velocity, leakage rate, and leakage volume under the hydromechanical coupling of the fracture-inner system were clarified according to the geometric governing of the natural fracture morphology. Finally, the dual-system coupling leakage model was developed considering the continuous equation, while the numerical solution was obtained through a time-step deduction. Results show that at a given time, a greater formation permeability leads to a greater leakage rate and volume, with a smaller leakage front distance. The leakage rate increases with an increase in formation permeability, well bottom differential pressure, and initial width of the natural fracture, while it decreases with an increase in the fracture normal stiffness, yield stress, and plastic viscosity. The new leakage model and numerical method concerning time-step deduction are assessed by solving the issues of fully coupled fracture-wall and fracture-inner systems considering drilling fluid leak-off. The new model may be utilized to simulate various problems related to the invasion of drilling fluids into the fractures, including predicting the dynamic width of natural fracture and borehole ballooning/breathing phenomena.
\end{abstract}

\section{Introduction}

According to statistics, the economic loss caused by lost circulation in the global oil industry exceeds hundreds of millions of dollars every year [1], and the leakage plugging cost of fractured formations accounts for more than $90 \%$ of the total cost of lost circulation [2]. For example, the time-loss caused by lost circulation during the drilling of ultradeep wells in western Sichuan is $8 \%$. By analyzing the drilling fluid leakage data and understanding drilling mud leakage, we can judge and evaluate the fracture development characteristics in the formation and provide the required parameters for subsequent leakage plugging operations [3-8]. When drilling mud loss occurs in naturally fractured formations, Sanfillippo et al. proposed an analytical model using Newtonian fluid to describe the leakage, neglecting the effect of the rheological properties of drilling mud [9]. Lietard et al. and Majidi et al. developed models for the radial flow of nonNewtonian fluid into a single natural fracture, neglecting the effect of drilling fluid leak-off and fracture deformability [10-12]. Other researchers have proposed an elastic equation to incorporate the impact of the fracture deformability, which relates the fracture width variation to the local pressure through the fracture normal stiffness [13-19]. To analyze fluid leak-off, Bychina conducted threshold processing for this leak-off process; that is, when the well-bottom 
differential pressure is greater than a fixed value, the fluid seeps into the formation at a certain leak-off velocity [20]. Razavi et al. described this with the Cater model [21]. Their research shows that for permeable fractured formations, considering the impact of the fluid, the leak-off effect is necessary for a realistic characterization of the leakage. However, the above model does not consider the porous elastic media characteristics of naturally permeable fractures and the hydromechanical coupling effect of the fracture-wall. When drilling mud loss occurs in a naturally fractured formation, the initial flowing net pressure field inside the fracture causes fracture deformation and leak-off, and reaction pressure is generated. Due to the flowing net pressure, the leak-off of the drilling fluid inside the fracture permeates into the formation region close to the fracture-wall, changing the formation pore pressure and redistributing the corresponding stress field. The time-dependent disturbed stress field arising from the coupled hydromechanical process changes the natural fracture width. The dynamic width of natural fractures is determined by changes in the deformed stress field of the fracture-wall and correspondingly influences the variation of the flowing net-pressure field inside the fracture. This is the joint effect of dual-system hydromechanical coupling between the fracture-wall and fracture-inner systems. In this work, it develops a new leakage model based on the poroelastic characteristics of the fracture-wall system and geometric governing equations of the fracture-inner system. The model considers the hydromechanical coupling effects between the aforementioned dual systems and provides a realistic characterization of the drilling mud loss in a naturally fractured formation. Besides, it also delineates the variations concerning the influence of multiple factors on the leakage state.

\section{Hydromechanical Coupling of Fracture- Wall System}

When drilling mud loss occurs in a naturally fractured formation, owing to drilling fluid leak-off, the hydromechanical coupling effect of the natural fracture-wall should be analyzed to understand the characteristics of the porous elastic medium and meet the governing equations of solid and fluid phases.

(1) Solid governing equations

Stress equilibrium equation ignoring the body force.

$$
\sum_{j=1}^{3} \frac{\partial \sigma_{i j}}{\partial x_{j}}=0 ; \sigma_{i j}=\sigma_{j i}
$$

where $\sigma_{i j}$ is the component of total stress tensor in MPa.

Strain-displacement equation (positive strain indicates compression).

$$
\varepsilon_{i j}=-\frac{1}{2}\left(u_{i, j}+u_{j, i}\right)
$$

where $\varepsilon_{i j}$ is the component of the bulk strain tensor and $u_{i, j}$ is the component of the deformation tensor in $\mathrm{m}$.

Strain-stress-pressure equation

$$
\varepsilon_{i j}=\left(\frac{1+v}{E}\right) \sigma_{i j}-\frac{v}{E} \sigma_{K K} \delta_{i j}-\frac{\alpha}{3 K} p \delta_{i j}
$$

where $\sigma_{K K}=\sigma_{x x}+\sigma_{y y}+\sigma_{z z}$ and $\delta_{i j}, E, v$, and $p$ are the Kronecker symbol, Young's modulus in $\mathrm{MPa}$, Poisson's ratio, and fluid pressure in $\mathrm{MPa}$, respectively. Other constants include the bulk modulus $K=E / 3(1-2 v)$ in $\mathrm{MPa}$, Biot coefficient $\alpha=1-K / K_{s}$, and $K_{s}$ is Particle volume modulus in $\mathrm{MPa}$.

From the above equation, the stress-strain-pressure is

$$
\sigma_{i j}=2 G \varepsilon_{i j}+\lambda \varepsilon_{e} \delta_{i j}+\alpha p \delta_{i j}
$$

where $\varepsilon_{e}$ is the volumetric strain defined by $\varepsilon_{e}=\varepsilon_{x}+\varepsilon_{y}+\varepsilon_{z}$, the shear modulus $G$ is $G=E / 2(1+v)$ in $\mathrm{MPa}$, and $\lambda$ is the Lame coefficient defined by $\lambda=K-2 / 3 G$ in $\mathrm{MPa}$. gives

Substituting Eq. (4) into Eq. (1) while considering Eq. (2)

$$
\sum_{j=1}^{3} \frac{\partial}{\partial x_{j}}\left\{-G\left(\frac{\partial u_{i}}{\partial x_{j}}+\frac{\partial u_{j}}{\partial x_{i}}\right)\right\}=\frac{\partial\left(-\alpha p-\lambda \varepsilon_{e}\right)}{\partial x_{i}}
$$

Considering the relation between the volumetric strain $\varepsilon_{e}$ and the solid displacement vector $\vec{u}$,

$$
\varepsilon_{e}=-\nabla \cdot \vec{u}=-\sum_{j=1}^{3} \frac{\partial u_{j}}{\partial x_{j}}
$$

Furthermore, substituting Eq. (6) into Eq. (5) yields

$$
-G \nabla^{2} u_{i}+(\lambda+G) \frac{\partial \varepsilon_{e}}{\partial x_{i}}+\alpha \frac{\partial p_{i}}{\partial x_{i}}=0
$$

(2) Fluid governing equations

Mass conservation, Darcy's law, and the state equation of the pore fluid in the formation region next to the natural fracture-wall are porous medium and are expressed as follows:

Mass conservation

$$
\nabla \cdot\left(\rho \phi \overrightarrow{v_{f}}\right)+\frac{\partial(\phi \rho)}{\partial t}=0
$$

Darcy's law [22] is written as

$$
\overrightarrow{v_{r}}=\phi\left(\overrightarrow{v_{f}}-\overrightarrow{v_{s}}\right)=-\frac{\kappa}{\mu} \nabla p .
$$


The state equation reads as

$$
c_{f}=\frac{1}{\rho} \frac{\partial \rho}{\partial p}
$$

In Eqs. (8) through (10), $\rho$ is the fluid density in $\mathrm{kg} / \mathrm{m}^{3}, \phi$ is porosity expressed as a percentage, $\overrightarrow{v_{f}}$ is the fluid velocity vector in $\mathrm{m} / \mathrm{s}, t$ is time in $\mathrm{s}, \overrightarrow{v_{s}}$ is solid velocity vector in $\mathrm{m} / \mathrm{s}, \mu$ is fluid viscosity in $\mathrm{Pa} \cdot \mathrm{s}, \boldsymbol{\kappa}$ is the formation permeability in $\mu \mathrm{m}^{2}, p$ is the fluid pressure in $\mathrm{Pa}$, and $c_{f}$ is the fluid compressibility in $\mathrm{MPa}^{-1}$.

Decomposing $\overrightarrow{v_{s j}}$ and $\overrightarrow{v_{r j}}(j=1,2,3)$ into three directions and considering Eqs. (8) and (9), one obtains

$$
\sum_{i=1}^{3} \frac{\partial}{\partial x_{i}} \bullet\left(\rho_{f}\left(\overrightarrow{v_{r j}}+\phi \overrightarrow{v_{s j}}\right)\right)+\frac{\partial\left(\phi \rho_{f}\right)}{\partial t}=0
$$

Using the material derivative $d(\bullet) / d t=\partial(\bullet) / \partial t+\overrightarrow{v_{s}} \cdot \nabla$ (•), Eq. (11) can be rearranged as

$$
\phi \frac{1}{\rho_{f}} \frac{d \rho_{f}}{\partial t}+\frac{d \phi}{\partial t}+\phi \sum_{i=1}^{3} \frac{\partial v_{s i}}{\partial x_{i}}+\sum_{i=1}^{3} \frac{\partial}{\partial x_{i}} \bullet\left(\overrightarrow{v_{r j}}\right)=0 .
$$

Equation (12) is further expressed as

$$
-\alpha \frac{d \varepsilon_{e}}{d t}+\left(\phi c_{f}+\frac{\alpha-\phi}{K_{s}}\right) \frac{d p}{d t}-\frac{\kappa}{\mu} \nabla^{2} p=0,
$$

when the four relations of fluid compressibility $\left(1 / \rho_{f}\right)(d$ $\left.\rho_{f} / \partial t\right)=c_{f}(d p / d t), \quad d \phi / \partial t=-(\alpha-\phi)\left(d \varepsilon_{e} / d t\right)+\left(\alpha-\phi / K_{s}\right)(d$ $p / d t), \sum_{i=1}^{3}\left(\partial v_{s i} / \partial x_{i}\right)=-d \varepsilon_{e} / d t$, and $\left(\partial / \partial x_{i}\right) \bullet(-(\kappa / \mu) \nabla p)=-$ $(\kappa / \mu) \nabla^{2} p$ related to the fluid leak-off occurring only along the fracture-wall are considered.

(3) Leak-off velocity equation under fracture-wall hydromechanical coupling

For the first term in Eq. (7), the solid displacement is a nonrotational field; therefore,

$$
\nabla^{2} u_{i}=-\frac{\partial \varepsilon_{e}}{\partial x_{i}}
$$

Substituting Eq. (14) into Eq. (7) and integrating it obtains

$$
\varepsilon_{e}=-\frac{1}{K+4 G / 3} \alpha p
$$

Substituting Eq. (15) into Eq. (13) yields

$$
\frac{1}{c_{\Pi}} \frac{d p}{d t}-\nabla^{2} p=0
$$

where $c_{\Pi}=M(K+4 G / 3) \kappa / \mu / K+4 G / 3+\alpha^{2} M$ in which the Biot modulus $M$ is defined by $1 / M=\phi c_{f}+\left(\alpha-\phi / K_{s}\right)$.

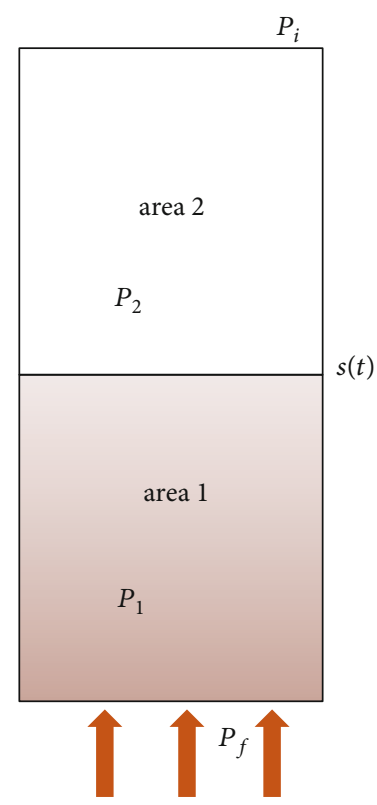

FIgURE 1: Schematic diagram of fracture-wall hydromechanical coupling.

As leak-off occurs only along the fracture-wall (along the Z-direction), it is described by radial coordinates; thus,

$$
\left\{\begin{array}{l}
\frac{\partial^{2} p}{\partial z^{2}}=\frac{1}{c_{\Pi}} \frac{\partial p}{\partial t}, \\
p=p_{i}(t=0, \quad z>0), \\
p=p_{f}(z=0, t>0), \\
p=p_{i}(z \rightarrow \infty, t>0),
\end{array}\right.
$$

where $\xi=z / \sqrt{4 c_{\Pi} t}$, by substituting it into the above equation, one obtains ( $c$ is an undetermined coefficient)

$$
\frac{\partial p}{\partial \xi}=c e^{-\xi^{2}}
$$

As shown in Figure 1, the natural fracture leak-off is divided into two areas, namely, the drilling fluid invasion area (area 1) and original formation area (area 2). The pressure distribution in the corresponding areas is represented by $p_{1}$ and $p_{2}$, respectively. The fluid viscosities of the two areas are the drilling fluid viscosity $\mu_{l}$ and the formation viscosity $\mu$, respectively. The term $s(t)$ indicates the contact surface of the two areas; where for area $1, c_{I}=$ $M(K+4 G / 3) \kappa /\left(K+4 G / 3+\alpha^{2} M\right) \mu_{l}, \omega=z / \sqrt{4 c_{I} t}$. Owing to the continuous pressure and mass distribution on the contact surface, the boundary conditions of the contact surface are given by Eqs. (19) and (20).

$$
\begin{gathered}
p_{1}(s)=p_{2}(s) \\
-\left.\frac{\kappa}{\mu_{l}} \frac{\partial p_{1}}{\partial z}\right|_{z=s(t)}=-\left.\frac{\kappa}{\mu} \frac{\partial p_{2}}{\partial z}\right|_{z=s(t)}=\phi \frac{d s(t)}{d t} .
\end{gathered}
$$




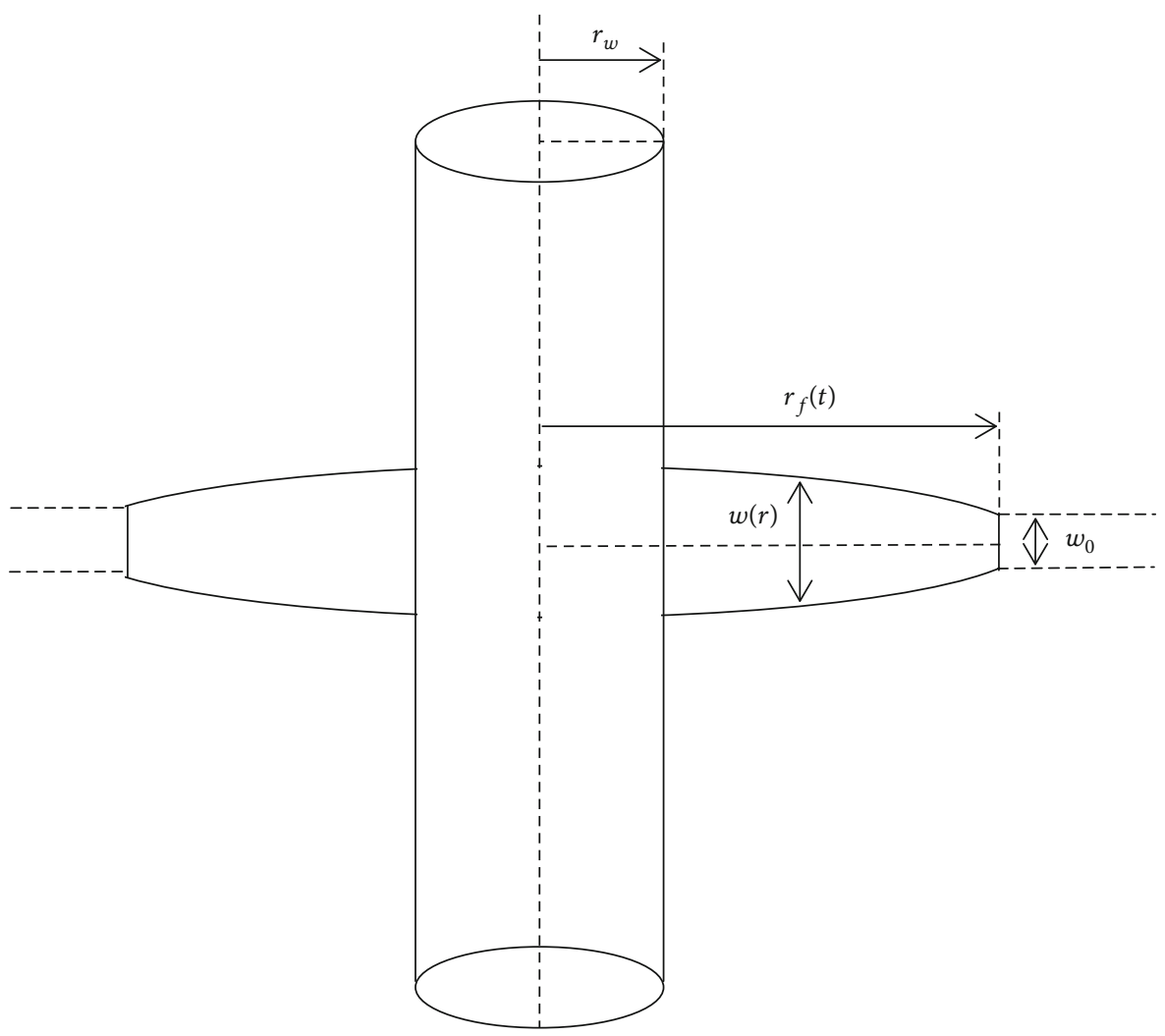

(a) Elevation view

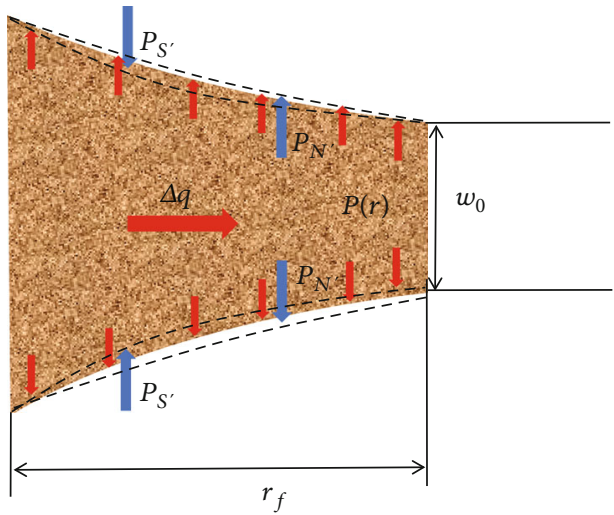

(b) Local view

Figure 2: Schematic diagram of fracture inner hydromechanical coupling.

The pressure $p_{1}$ of area 1 and $p_{2}$ of area 2 are calculated by Eq. (18). Combining the boundary condition in Eq. (19), the pressure at the contact surface $s(t)$ is

$$
p_{f}+c_{1} \frac{\sqrt{\pi}}{2} \operatorname{erf}(\varpi)=p_{i}-c_{2} \frac{\sqrt{\pi}}{2} \operatorname{erfc}(\xi)
$$

where $\operatorname{erf}(\xi)$ is the error function, $\operatorname{erfc}(\xi)$ is the complementary error function, and $\operatorname{erfc}(\xi)=1-\operatorname{erf}(\xi)$. To ensure that Eq. (21) is applicable at all times, $\eta$ can be set as an undetermined coefficient. The terms $\eta$ and $s(t)$ have the following relationship:

$$
s(t)=\eta \sqrt{t} .
$$

$c_{1}=-\left(\phi \eta \mu_{l} \sqrt{c_{I}} / \kappa\right) e^{\left(\eta / \sqrt{4 c_{I}}\right)^{2}}$ and $c_{2}=-\left(\phi \eta \mu \sqrt{c_{\Pi}} / \kappa\right) e^{\left(\eta / \sqrt{4 c_{\Pi}}\right)^{2}}$ are obtained by the boundary conditions in Eq. (20). Substituting them and Eq. (22) into Eq. (21) yields

$$
\begin{aligned}
p_{f}-p_{i}= & \frac{\sqrt{\pi}}{2} \frac{\phi \eta}{\kappa}\left(\mu_{l} \sqrt{c_{I}} e^{\left(\eta / \sqrt{4 c_{I}}\right)^{2}} \operatorname{erf}\left(\frac{\eta}{\sqrt{4 c_{I}}}\right)\right. \\
& \left.+\mu \sqrt{c_{\Pi}} e^{\left(\eta / \sqrt{4 c_{I}}\right)^{2}} \operatorname{erfc}\left(\frac{\eta}{\sqrt{4 c_{\Pi}}}\right)\right) .
\end{aligned}
$$


Based on Eq. (23), the dichotomy method is used to solve for the undetermined coefficient $\eta$, yielding $c_{1}$. Therefore, the drilling mud leak-off velocity under the fracture-wall hydromechanical coupling is

$$
u_{l}=-\left.\frac{\kappa}{\mu_{l}} \frac{d p_{1}}{d z}\right|_{x=0}=-\frac{\kappa}{\mu_{l}} \frac{c_{1}}{\sqrt{4 c_{I} t}} .
$$

Letting $c_{1}=-2 \Delta p / \sqrt{\varsigma}$ and substituting it into Eq. (24) yields

$$
u_{l}=\frac{\kappa}{\mu_{l}} \frac{\Delta p}{\sqrt{\varsigma c_{I} t}}
$$

where $\varsigma$ is the harmonic coefficient of the leak-off velocity. As leak-off occurs in both the upper and lower sides of the fracture-wall, the total leak-off velocity equation is

$$
u_{L}=2 u_{l}=\frac{2 \kappa}{\mu_{l}} \frac{\Delta p}{\sqrt{\varsigma c_{I} t}}
$$

where $u_{L}$ is drilling fluid leak-off velocity in $\mathrm{m} / \mathrm{s}$.

\section{Hydromechanical Coupling of Fracture- Inner System}

When drilling mud loss occurs in a naturally fractured formation, this can be a penny-shaped natural fracture with an infinitely large radius $[11,18,20,21]$ (see Figure 2(a)). The initial flowing net pressure inside the fracture $p_{N}{ }^{\prime}$ causes fracture deformation and leakage and correspondingly produces the reaction pressure $p_{S}{ }^{\prime}$. The superposition of pressures $p_{N}{ }^{\prime}$ and $p_{S}{ }^{\prime}$ further yields the flowing net pressure inside the fracture $p(r)$ (see Figure 2(b)).

The flowing net pressure inside the fracture $p(r)$ acts on the natural fracture-wall, causing it to deform. The linear deformation rule yields Eq. (27) [16, 17, 19]. In Eq. (27), the natural fracture is assumed to have a nonzero fracture width $\left(w_{0}\right)$ at zero overpressure, which implies that the natural fracture remains open at the formation of pore pressure [23-25].

$$
w(r)=w_{0}+\frac{p(r)}{K_{\mathrm{Frac}}},
$$

where $w(r)$ is the dynamic width of natural fracture in $\mathrm{m}$, $w_{0}$ is the initial width of the fracture (natural fracture width at $p(r)=0)$ in $\mathrm{m}$, and $p(r)$ is the net pressure flowing inside the fracture in $\mathrm{MPa}$. The term $K_{\mathrm{Frac}}$ is the fracture normal stiffness in $\mathrm{MPa} / \mathrm{m}$. The flowing net pressure inside the fracture along the radial direction is [21]

$$
p(r)=\Delta p\left[1-\left(\frac{r-r_{w}}{r_{f}(t)-r_{w}}\right)\right]^{C(t)}
$$

where $\Delta p$ is the well bottom differential pressure in $\mathrm{MPa}$. $C(t)$ is the dimensionless morphological index coefficient

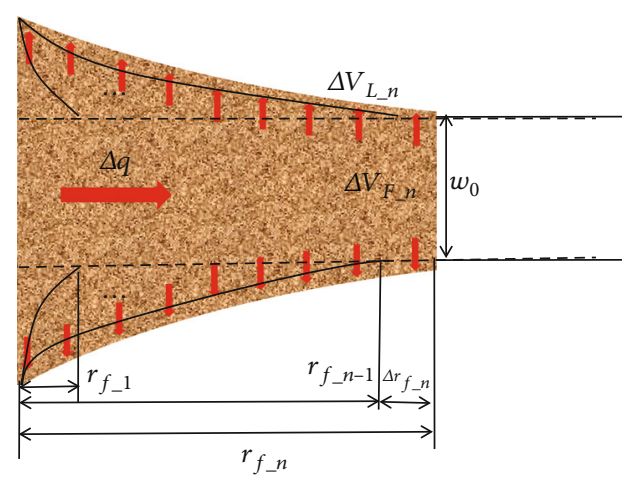

FIgURE 3: Schematic diagram of the increment of drilling mud loss in a naturally fractured formation within $\Delta \mathrm{t}$.

of the natural fracture, and $r_{f}(t)$ is the distance to the leakage front in $\mathrm{m}$.

By analyzing Eq. (28), at the fracture opening $\left(r=r_{w}\right), p$ $(r)=\Delta p$ is the well bottom differential pressure; at the leakage front distance $\left(r=r_{f}\right), p(r)=0$ is the internal pressure in the original fracture. Both the morphologic index coefficient of natural fracture $C(t)$ and the leakage front distance $r_{f}(t)$ are time functions, which are hereinafter referred to as $C$ and $r_{f}$. Substituting Eq. (28) into Eq. (27), the radial distribution of the dynamic width of the natural fracture is

$$
w(r)=w_{0}+\frac{\Delta p}{K_{\mathrm{Frac}}}\left[1-\left(\frac{r-r_{w}}{r_{f}-r_{w}}\right)\right]^{C} .
$$

When drilling mud loss occurs in a naturally fractured formation, the leakage front distance $r_{f}$ increases from $r_{f_{-} n-1}$ to $r_{f_{-} n}$ (i.e., time $\left.(n-1) \Delta t \rightarrow n \Delta t\right)$, and the increment of the drilling fluid loss volume $\Delta V_{n}$ within $\Delta t$ is divided into two parts: the leakage volume increment $\Delta V_{F_{-} n}$ due to the deformation of the natural fracture and the increase in the distance to the leakage front, and the leak-off volume increment $\Delta V_{L_{-} n}$ of the permeable fracture-wall (see Figure 3).

According to the above analysis, $\Delta V_{-n}$ is obtained based on mass conservation

$$
\Delta V_{-n}=\Delta V_{F_{-} n}+\Delta V_{L_{-} n},
$$

where $\Delta V_{F_{-} n}$ is solved by the following equation

$$
\Delta V_{F \_n}=\int_{r_{f \_n-1}}^{r_{f \_n}} 2 \pi r w d r,
$$

where $r_{f_{-} n}$ is leakage front distance at $t=n \Delta t$ in $\mathrm{m}$.

Based on the leak-off velocity Eq. (26), $\Delta V_{L_{-} n}$ is expressed as

$$
\Delta V_{L \_n}=u_{L} \times \Delta A=\int_{r_{f-n-1}}^{r_{f \_n}} 2 \pi r^{*} u_{L}\left(r^{*}, t^{*}\right) d r^{*}
$$

where $\Delta A$ is the increment leak-off area within $\Delta t, \mathrm{~m}^{2}$. 


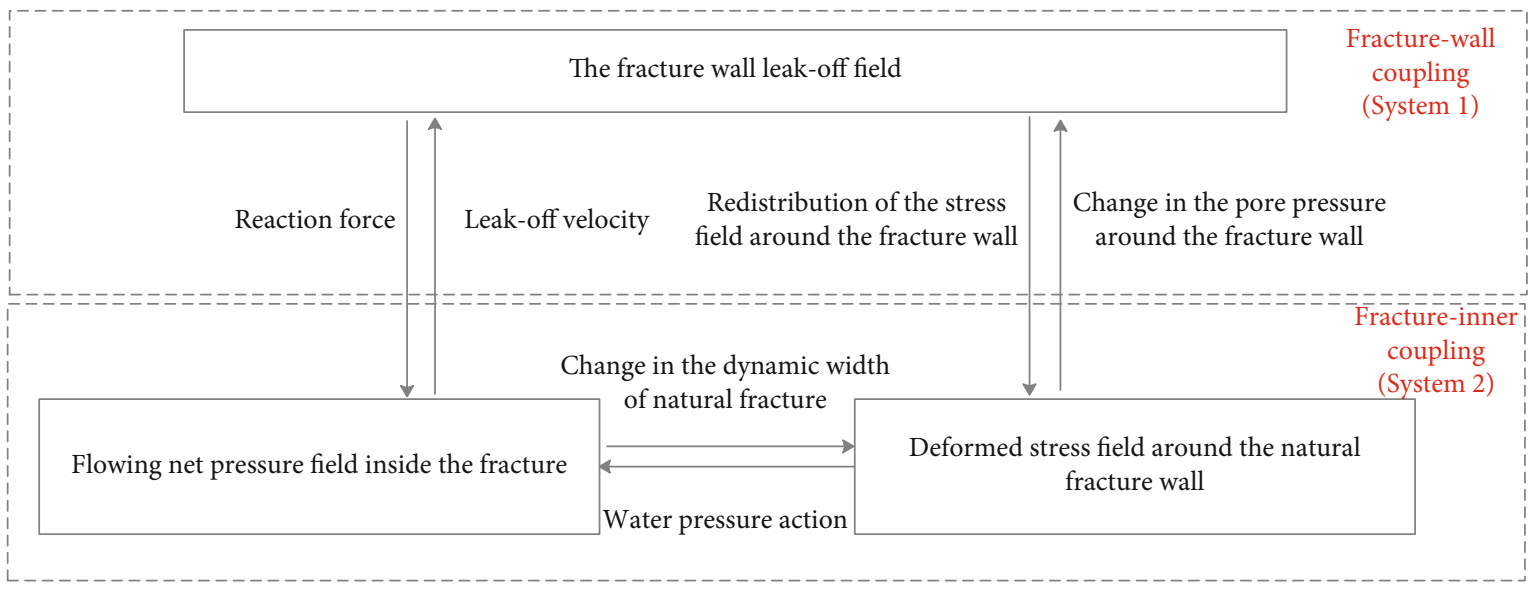

Figure 4: Schematic diagram of dual-system coupling.

The geometric governing equation of the leakage invasion velocity at any location $r\left(r \in\left[r_{w}, r_{f}\right]\right.$ where $r_{f}$ is the leakage front distance) is written as

$$
v_{m}(r, t)=\frac{q(r, t)}{2 \pi r w}=\frac{d\left(V_{F}(t)+V_{L}(r, t)\right) / d t}{2 \pi r w} .
$$

At this point, the total leakage volume $V_{F}(t)$ due to the deformation of the natural fracture and increase in the distance to the leakage front is

$$
V_{F}(t)=\int_{r_{W}}^{r_{f}} 2 \pi r w d r
$$

Meanwhile, the leak-off volume at the leakage distance $r$ is the total leak-off volume within $t$ minus the leak-off volume before leakage distance $r ; V_{L}(r, t)$ is expressed as

$$
\begin{aligned}
V_{L}(r, t)= & \int_{0}^{t} \int_{r_{w}}^{r_{f}} 2 \pi r^{*} u_{L}\left(r^{*}, t^{*}\right) d r^{*} d t \\
& -\int_{0}^{t} \int_{r_{w}}^{r} 2 \pi r^{*} u_{L}\left(r^{*}, t^{*}\right) d r^{*} d t \\
= & \int_{0}^{t} \int_{r}^{r_{f}} 2 \pi r^{*} u_{L}\left(r^{*}, t^{*}\right) d r^{*} d t
\end{aligned}
$$

By substituting Eqs. (29), (34), and (35) into Eq. (33), the geometric governing equation of the leakage rate is

$$
q(r, t)=Q \frac{d r_{f}}{d t}+\int_{r}^{r_{f}} 2 \pi r^{*} u_{L}\left(r^{*}, t\right) d r^{*}
$$

where the expression of $Q$ is

$$
Q=2 \pi w_{0} r_{f}+\frac{2 \pi \Delta p}{[C+1][C+2] K_{\mathrm{Frac}}}\left(2 r_{f}+C r_{w}\right)
$$

Substituting the leak-off velocity $u_{L}\left(r^{*}, t\right)$ from Eq. (26) into Eq. (36) yields

$$
q(r, t)=Q \frac{d r_{f}}{d t}+\int_{r}^{r_{f}} \frac{4 \pi \kappa p(r)}{\mu_{l} \sqrt{\varsigma c_{I}}} \frac{r^{*}}{\sqrt{t-\tau\left(r^{*}\right)}} d r^{*}
$$

where $\tau$ is the time required to reach the leakage distance $r^{*}$. Substituting Eq. (38) into Eq. (33) yields the expression of the geometric governing equation of leakage invasion velocity

$$
v_{m}(r, t)=\frac{Q\left(d r_{f} / d t\right)+\int_{r}^{r_{f}}\left(4 \pi \kappa p(r) / \mu_{l} \sqrt{\varsigma \mathcal{C}_{I}}\right)\left(r^{*} / \sqrt{t-\tau\left(r^{*}\right)}\right) d r^{*}}{2 \pi r w} .
$$

\section{Leakage Coupling Model for Dual Systems}

When leakage occurs in a naturally fractured formation, it includes two sets of coupling systems for this process, the fracture-wall system (coupling system 1) and fracture-inner system (coupling system 2). The initial flowing net pressure field inside the fracture causes the leak-off and deformation of the fracture. Meanwhile, reaction pressure is generated. Due to the flowing net pressure, the leaked drilling fluid inside the fracture permeates into the formation close to the fracture-wall and changes the formation pore pressure; this causes the corresponding stress field to redistribute. The time-dependent disturbed stress field arising from the coupled hydromechanical process changes the natural fracture width. The dynamic width of a natural fracture is determined by changes in the deformed stress field of the fracture-wall and correspondingly reacts to variations of the flowing net-pressure field inside the fracture. The link between the two coupled systems of the formation and fracture is the flowing net pressure inside the fracture, which determines the dynamic width of the natural fracture and leak-off velocity (see Figure 4). 


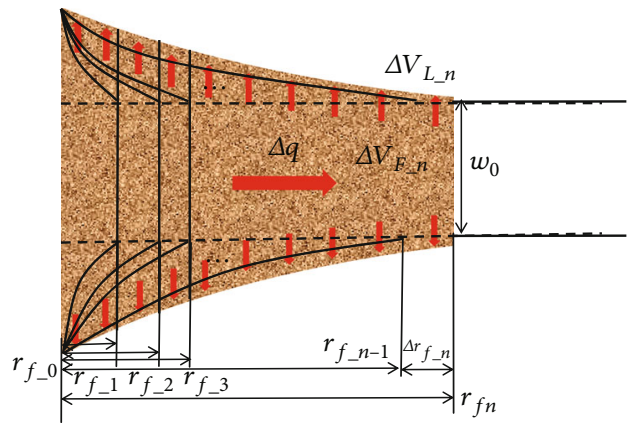

FIGURE 5: Schematic diagram of drilling mud loss in naturally fractured formation segments.

When drilling mud loss occurs in a naturally fractured formation, the pressure gradient inside the fracture of the Bingham fluid model is [11]

$$
\frac{d p}{d r}=\frac{12 \mu_{p} v_{m}}{w^{2}}+\frac{3 \tau_{y}}{w} .
$$

Substituting the geometric governing equation of the leakage invasion velocity Eq. (39) into Eq. (40), integrating $r$ from $r_{w} \longrightarrow r_{f}$, and combining the flowing net pressure inside the fracture $p(r)$ Eq. (28), the well bottom differential pressure $\Delta p$ is written as

$\Delta p=\int_{r_{w}}^{r_{f}}\left[\frac{12 \mu_{p} Q\left(d r_{f} / d t\right)+\int_{r}^{r_{f}}\left(4 \pi \kappa p(r) / \mu_{l} \sqrt{\epsilon_{I}}\right)\left(r^{*} / \sqrt{t-\tau\left(r^{*}\right)}\right) d r^{*}}{2 \pi r w}+\frac{3 \tau_{y}}{w}\right] d r$.

After integrating Eq. (41), the well-bottom differential pressure $\Delta p$ is given by

$$
\begin{aligned}
\Delta P= & \frac{6 \mu_{p}}{\pi} Q F_{1}\left(r_{f}\right) \frac{d r_{f}}{d t}+3 \tau_{y} F_{2}\left(r_{f}\right)+\frac{6 \mu_{p}}{\pi} \int_{r_{w}}^{r_{f}} \frac{1}{r w^{3}}\left(\frac{1}{r_{f}-r_{w}}\right)^{C} \\
& \cdot \int_{r}^{r_{f}} \frac{\chi_{I}\left(r_{f}-r^{*}\right)^{C} r^{*}}{\sqrt{t-\tau\left(r^{*}\right)}} d r^{*} d r,
\end{aligned}
$$

where $\chi_{I}=\left(4 \pi \kappa \Delta p / \mu_{l} \sqrt{\varsigma c_{I}}\right)$ and the expressions of $F_{1}\left(r_{f}\right)$ and $F_{2}\left(r_{f}\right)$ are described in Eqs. (43) and (44). Solving Eq. (42) and separating the geometric governing equation of the leakage front invasion velocity $d r_{f} / d t$ to the left of the equation, we obtain

$$
\begin{aligned}
F_{1}(r) & =\int_{r_{W}}^{r} \frac{1}{r w^{3}} d r=\int_{r_{w}}^{r} \frac{1}{r\left\{w_{0}+\left(\Delta p / K_{f r a c}\right)\left[1-\left(r-r_{w} / r_{f}-r_{w}\right)\right]^{c}\right\}^{3}} d r, \\
F_{2}(r) & =\int_{r_{w}}^{r} \frac{1}{w} d r=\int_{r_{w}}^{r} \frac{1}{w_{0}+\left(\Delta p / K_{\text {frac }}\right)\left[1-\left(r-r_{w} / r_{f}-r_{w}\right)\right]^{c}} d r, \\
\frac{d r_{f}}{d t} & =\frac{\Delta P-3 \tau_{y} F_{2}\left(r_{f}\right)-6 \mu_{p} / \pi \int_{r_{w}}^{r_{f}}\left(1 / r w^{3}\right)\left(1 / r_{f}-r_{w}\right)^{C} \int_{r}^{r_{f}}\left(\chi_{I}\left(r_{f}-r^{*}\right)^{C} r^{*} / \sqrt{t-\tau\left(r^{*}\right)}\right) d r^{*} d r}{\left(6 \mu_{p} / \pi\right) Q F_{1}\left(r_{f}\right)} .
\end{aligned}
$$

The pressure distribution inside the fracture can be obtained from Eq. (45) as

$$
\begin{gathered}
p(r)=\Delta p-\frac{6 \mu_{p} Q}{\pi} F_{1}(r) \frac{d r_{f}}{d t}-3 \tau_{y} F_{2}(r)-\frac{6 \mu_{p}}{\pi} \int_{r_{w}}^{r} \frac{1}{r w^{3}} \\
\cdot\left(\frac{1}{r_{f}-r_{w}}\right) \int_{r}^{C} \frac{\chi_{I}\left(r_{f}-r^{*}\right)^{C} r^{*}}{\sqrt{t-\tau\left(r^{*}\right)}} d r^{*} d r .
\end{gathered}
$$

To solve Eqs. (45) and (46), the leakage time $t$ is divided into $n \Delta t$, that is, if $t=n \Delta t$, then $r_{f}=r_{f_{-} n}$. The leakage front distance increases from $r_{f_{-} n-1} \longrightarrow r_{f_{-} n}$ within $(n-1) \Delta t \longrightarrow n \Delta t$ (see Figure 5$)$. In this way, the spatial distance increment $\Delta r_{f_{-} n}$ corresponding to the time increment $\Delta t$ has the same leak-off velocity, which allows the equation to be solved in segments. The item $\int_{r_{w}}^{r} 1 / r w^{3}$ $\left(1 / r_{f}-r_{w}\right)^{C} \int_{r}^{r_{f}}\left(\chi_{I}\left(r_{f}-r^{*}\right)^{C} r^{*} / \sqrt{t-\tau\left(r^{*}\right)}\right) d r^{*} d r$ in Eq. (46) is processed by segments. At this point, the leakage front distance is $r_{f}$, and the upper limit of the integral is $r \in\left[r_{w}, r_{f}\right]$. The integrated domain is processed in segments and expressed as $\sum_{k=0}^{k=m} \int_{r_{f-k}}^{r_{f-k+1}} f(r) d r$, where $m \in[0, n-1]$ is an integer; then, this item can be expressed as

$$
\begin{aligned}
& \int_{r_{w}}^{r} \frac{1}{r w^{3}}\left(\frac{1}{r_{f}-r_{w}}\right)^{C} \int_{r}^{r_{f}} \frac{\chi_{I}\left(r_{f}-r^{*}\right)^{C} r^{*}}{\sqrt{t-\tau\left(r^{*}\right)}} d r^{*} d r \\
& =\sum_{k=0}^{k=m} \int_{r_{f\lrcorner k}}^{r_{f-k+1}} \frac{1}{r w^{3}}\left(\frac{1}{r_{f \_n}-r_{w}}\right)^{C} \int_{r}^{r_{f-n}} \frac{\chi_{I}\left(r_{f \_n}-r^{*}\right)^{C} r^{*}}{\sqrt{t-\tau\left(r^{*}\right)}} d r^{*} d r .
\end{aligned}
$$

By substituting Eq. (47) into Eqs. (46) and (45), we can obtain the expressions of the flowing net pressure inside the 


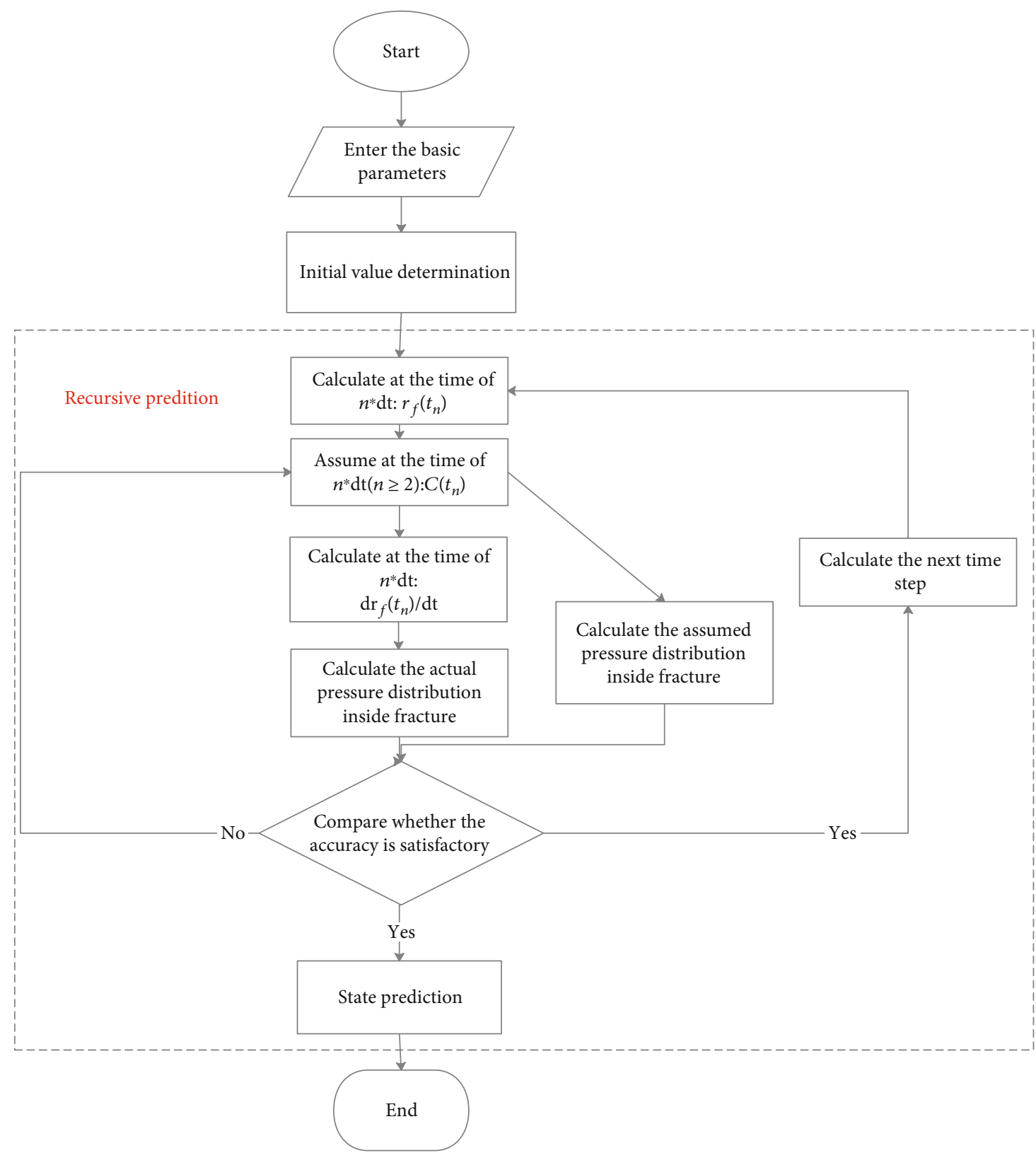

FIGURE 6: Schematic diagram for solving the dual-system coupling leakage model.

TABLE 1: Calculation parameters.

\begin{tabular}{lccccc}
\hline Parameter & Symbol & Value & Parameter & Symbol & Value \\
\hline Formation permeability (md) & $\kappa$ & $0 / 1 / 5 / 10$ & Yield stress $(\mathrm{Pa})$ & $\tau_{y}$ & 15 \\
Formation fluid viscosity (Pa.S) & $\mu$ & $10^{-3}$ & Plastic viscosity (mPa.S) & 39 \\
Elasticity modulus (MPa) & $E$ & $10^{4}$ & Well bottom differential pressure $(\mathrm{MPa})$ & $\Delta p$ & 5 \\
Poisson's ratio (dimensionless) & $v$ & 0.22 & Initial width of a natural fracture $(\mu \mathrm{m})$ & $w_{0}$ & 800 \\
Particle volume modulus (MPa) & $K_{s}$ & $36 * 10^{3}$ & Fracture normal stiffness $(\mathrm{GPa} / \mathrm{m})$ & $K_{F r a c}$ & 30 \\
Pore fluid volume modulus (MPa) & $K_{f}$ & $2.25 * 10^{3}$ & Wellbore radius (mm) & $r_{w}$ & 155.6 \\
Formation porosity (dimensionless) & $\phi$ & 0.1 & & & \\
\hline
\end{tabular}


fracture and leakage front invasion velocity when the leakage front distance is $r_{f_{-} n}$, as follows:

$$
\begin{gathered}
p(r)=\Delta p-\frac{6 \mu_{p}}{\pi} Q F_{1}(r) \frac{d r_{f_{-} n}}{d t}-3 \tau_{y} F_{2}(r)-\frac{6 \mu_{p}}{\pi} \sum_{k=0}^{k=m} \int_{r_{f-k}}^{r_{f-k+1}} \frac{1}{r w^{3}}\left(\frac{1}{r_{f-n}-r_{w}}\right)^{C} \int_{r}^{r_{f-n}} \frac{\chi_{I}\left(r_{f_{-}-n}-r^{*}\right)^{C} r^{*}}{\sqrt{t-\tau\left(r^{*}\right)}} d r^{*} d r, \\
\frac{d r_{f_{-} n}}{d t}=\frac{\Delta p-3 \tau_{y} F_{2}\left(r_{f_{-} n}\right)-6 \mu_{p} / \pi \sum_{k=0}^{k=n-1} \int_{r_{f-k}}^{r_{f-k+1}}\left(1 / r w^{3}\right)\left(1 / r_{f \_n}-r_{w}\right)^{C} \int_{r}^{r_{f-n}}\left(\chi_{I}\left(r_{f_{-} n}-r^{*}\right)^{C} r^{*} / \sqrt{t-\tau\left(r^{*}\right)}\right) d r^{*} d r}{\left(6 \mu_{p} / \pi\right) Q F_{1}\left(r_{f_{-n}}\right)} .
\end{gathered}
$$

As shown in Eq. (28), performing segment manipulations of the expression of flowing net pressure inside the fracture yields the following expression of $t=n \Delta t, p(r)$ written as

$$
p(r)=\Delta p\left[1-\left(\frac{r-r_{w}}{r_{f_{-}}-r_{w}}\right)\right]^{C} .
$$

By Eq. (36), at a given time, we can obtain the leakage rate at any leakage distance. The leakage rate measured on the ground is the leakage rate at the fracture opening, that is, $q\left(r_{w}, t\right)$. Substituting the expression of $\Delta p_{L}$ into Eq. (36) and calculating it by segments, we obtain $q\left(r_{w}, t\right)$

$$
\begin{aligned}
q\left(r_{w}, t_{n}\right)= & Q \frac{d r_{f \_n}}{d t}+\frac{1}{\left(r_{f \_n}-r_{w}\right)^{C}} \times \sum_{k=0}^{k=n-1} \frac{\chi_{I \_k}}{\sqrt{(n-k) \Delta t}} \\
& \cdot\left(\frac{\left(r_{f \_n}-r_{f \_k}\right)^{C+1}\left(C r_{f \_k}+r_{f \_k}+r_{f \_n}\right)}{C^{2}+3 C+2}\right. \\
& \left.-\frac{\left(r_{f \_n}-r_{f \_k+1}\right)^{C+1}\left(C r_{f \_k+1}+r_{f \_k+1}+r_{f \_n}\right)}{C^{2}+3 C+2}\right),
\end{aligned}
$$

where $\chi_{I_{-k}}=4 \pi \kappa \Delta p / \mu_{l} \sqrt{\varsigma_{-k} \mathcal{C}_{I}}, \varsigma_{-k}$ is calculated by the flowing net pressure inside the fracture of each spatial distance $\Delta r_{f_{-n}}$ in any period of time $\Delta t$ (set $\left.\Delta t=0.001 \mathrm{~s}\right)$. At a given time, the total leak-off volume is $V_{L}\left(r_{w}, t\right)=\sum_{j=1}^{j=n}$ $q_{L_{-j}} \Delta t$, calculates it by segments provides $V_{L}\left(r_{w}, t_{n}\right)$

$$
\begin{aligned}
V_{L}\left(r_{w}, t_{n}\right)= & \sum_{j=1}^{j=n} \frac{1}{\left(r_{f_{-j}}-r_{w}\right)^{C}} \sum_{k=0}^{k=j-1} \frac{\chi_{I_{-} \sqrt{\Delta t}}}{\sqrt{(j-k)}} \\
& \cdot\left[\begin{array}{l}
\frac{\left(r_{f_{-j}}-r_{f \_k}\right)^{C+1}\left(C r_{f \_k}+r_{f \_k}+r_{f-j}\right)}{C^{2}+3 C+2}- \\
\frac{\left(r_{f-j}-r_{f-k+1}\right)^{C+1}\left(C r_{f \_k+1}+r_{f_{-k+1}}+r_{f_{-j}}\right)}{C^{2}+3 C+2}
\end{array}\right] .
\end{aligned}
$$

As seen from Eq. (30), the total leakage volume measured on the ground is the sum of the two parts of $V_{L}$ $\left(r_{w}, t_{n}\right)$ and $V_{F}\left(t_{n}\right)$

$$
V_{\text {Total }}\left(t_{n}\right)=V_{L}\left(r_{w}, t_{n}\right)+V_{F}\left(t_{n}\right)
$$

The pressure inside the fracture solved by Eq. (48) is $p_{I}(r)$; the pressure inside fracture solved by Eq. (50) is $p_{I I}(r)$; the rationality of $C$ is determined by judging whether they satisfy the solution accuracy $\varepsilon_{P}=\mid p_{I}(r)-$ $p_{I I}(r) \mid / p_{I}(r)$. The whole solution process is divided into two steps "initial value determination" and "recursive prediction" (see Figure 6). The specific steps are as follows:

(1) Enter the basic parameters $\Delta p, \tau_{y}, \mu_{p}, w_{0}, K_{\text {Frac }}$, and basic formation parameters $\left(k, \mu, E, v, K_{s}\right.$, and $\left.K_{f}\right)$ to calculate the leak-off harmonic coefficient $\varsigma$

(2) Calculate $r_{f}\left(t_{1}\right)\left(t_{1}=\Delta t\right)$ by assuming that the initial value of $C$ is $C_{0}$. Calculate $d r_{f}\left(t_{1}\right) / d t$ by assuming $C$ $\left(t_{1}\right)$, combining it with $r_{f}\left(t_{1}\right)$ and substituting it into Eq. (49)

(3) Substitute $d r_{f}\left(t_{1}\right) / d t$ into Eq. (48) to calculate $p_{I}(r)$ and substitute $d r_{f}\left(t_{1}\right) / d t$ and $r_{f}\left(t_{1}\right)$ into Eq. (50) to calculate $p_{I I}(r)$ until the solution accuracy $\varepsilon_{p}$ is satisfied

(4) Compare $C_{0}$ and $C\left(t_{1}\right)$ to judge whether the solution accuracy $\varepsilon_{C}=\left|C_{0}-C\left(t_{1}\right)\right| / C_{0}$ is satisfied; if not, repeat step (2) until the solution accuracy $\varepsilon_{C}$ is satisfied

(5) Solve $r_{f}\left(t_{n}\right)=d r_{f}\left(t_{n-1}\right) / d t * \Delta t$ for the next time step, as per $d r_{f}\left(t_{n-1}\right) / d t(n \geq 2)$, solved by the previous time step. Assuming the value of $C\left(t_{n}\right)$, calculate $d r_{f}\left(t_{n}\right) / d t$ by combining it with $r_{f}\left(t_{n}\right)$ and substituting it into Eq. (49)

(6) Substitute $d r_{f}\left(t_{n}\right) / d t$ into Eq. (48) to calculate $p_{I}(r)$ and substitute $C\left(t_{n}\right)$ and $r_{f}\left(t_{n}\right)$ into Eq. (50) to calculate $p_{I I}(r)$ until the solution accuracy $\varepsilon_{p}$ is satisfied

(7) Substitute the calculated $r_{f}\left(t_{n}\right)$ and $C\left(t_{n}\right)$ into Eqs. (51), (34), (52), and (53) and calculate the leakage 


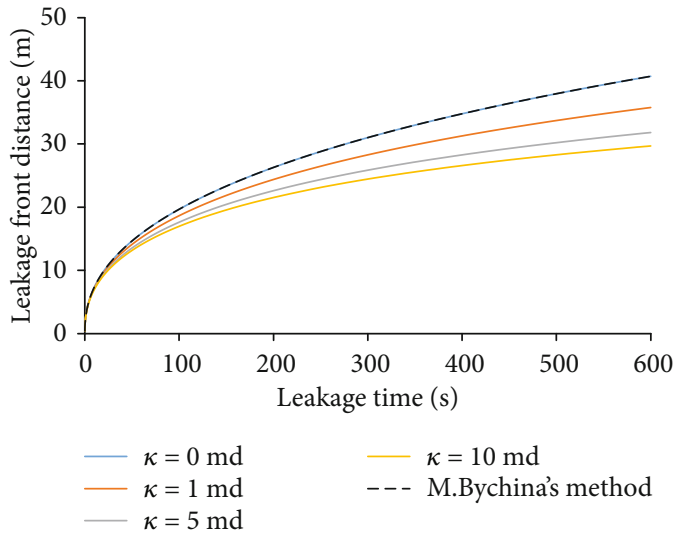

Figure 7: Leakage front distance graph under different permeability.

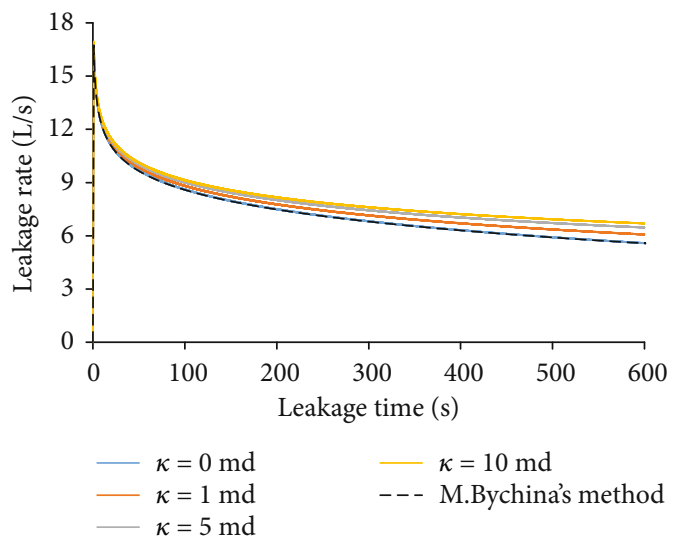

Figure 8: Leakage rate graph under different formation permeability.

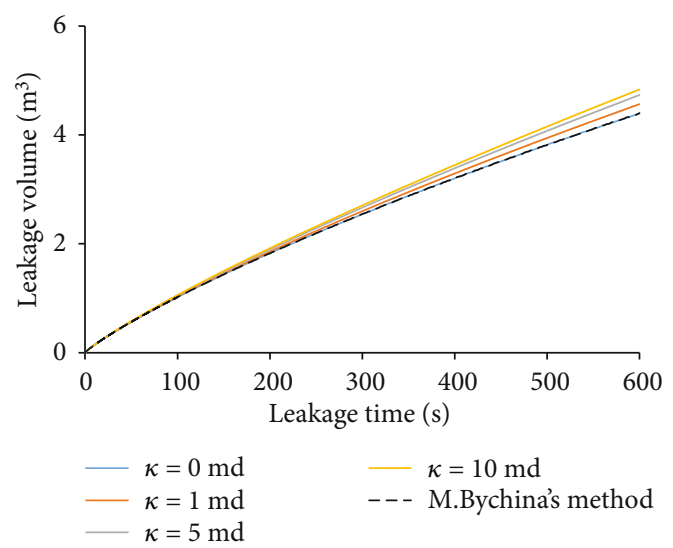

Figure 9: Leakage volume graph under different formation permeability.

rate $q\left(t_{n}\right)$, leakage volume inside fracture $V_{F}\left(t_{n}\right)$, leak-off volume $V_{L}\left(t_{n}\right)$, and total leakage volume $V_{\text {Total }}\left(t_{n}\right)$

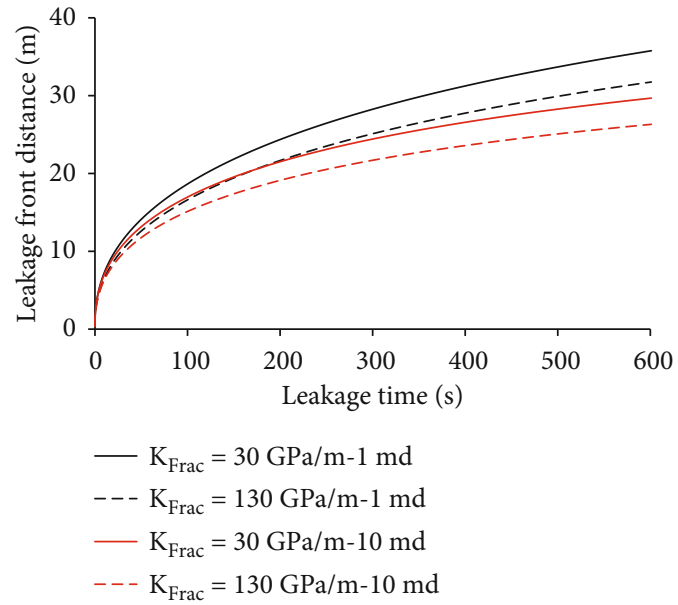

FIgURE 10: Leakage front distance under different formation permeability and fracture normal stiffness.

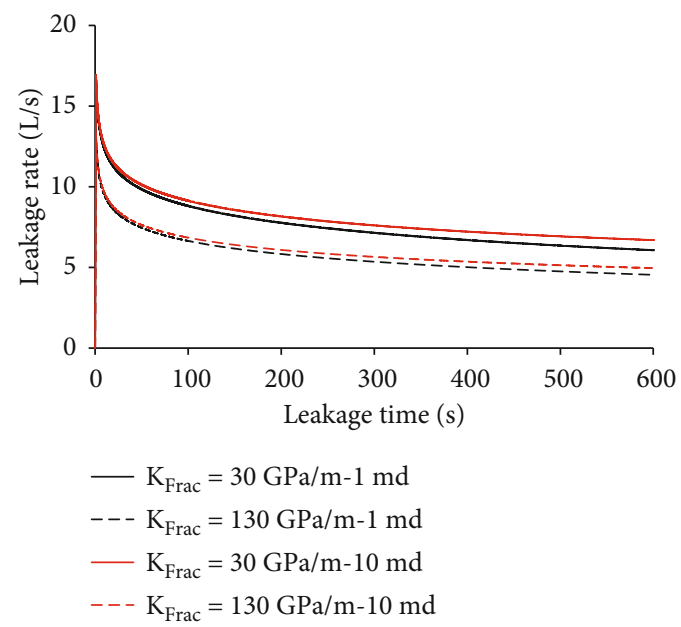

FIGURE 11: Leakage rate under different formation permeability and fracture normal stiffness.

Among them, steps (2)-(4) represent the "initial value determination" step, and steps (5)-(7) are the "recursive prediction" step.

\section{Leakage Simulation and Analysis of Influence Factors}

5.1. Method Verification and Leakage Simulation. To analyze the leakage state at different formation permeabilities, $\kappa$ was set as $0,1,5$, and $10 \mathrm{md}$. Other parameters are shown in Table 1. When $\kappa=0 \mathrm{md}$, the calculation results were compared with Bychina's [20] finite difference method to verify the correctness of the new model.

As shown in Figures 7-9, when $\kappa=0$ md, the calculation results of the proposed model are consistent with those of Bychina's finite difference method, which verifies the reliability of the model. At any given time, a greater formation permeability causes a greater leakage rate and volume, as well as 


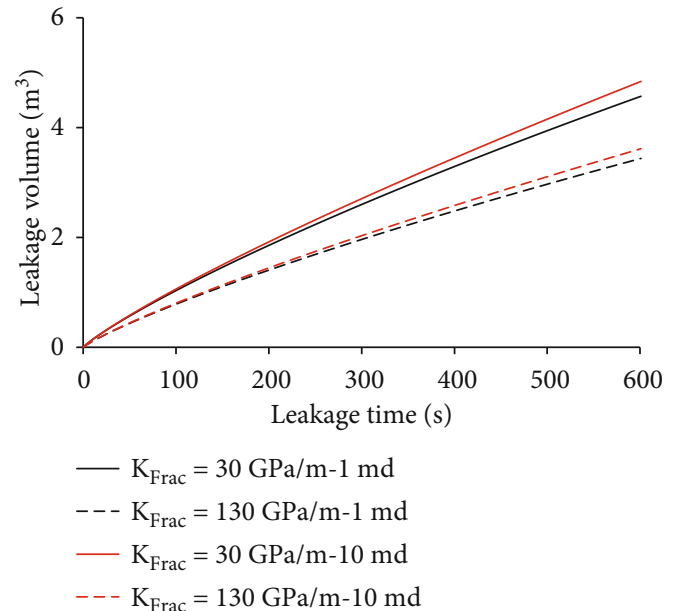

FIGURE 12: Leakage volume under different formation permeability and fracture normal stiffness.

TABLE 2: Influence of multiple factors.

\begin{tabular}{|c|c|c|c|c|}
\hline Affected object & & $\begin{array}{c}\text { Leakage front } \\
\text { distance } \\
r_{f} \\
\end{array}$ & $\begin{array}{c}\text { Leakage } \\
\text { rate } \\
q\end{array}$ & $\begin{array}{c}\text { Leakage } \\
\text { volume } \\
V_{\text {Total }}\end{array}$ \\
\hline \multicolumn{5}{|l|}{ Influence factor } \\
\hline \multirow[t]{3}{*}{ Fixed influencing factor } & $\uparrow \kappa$ & - & + & + \\
\hline & $\uparrow k_{\mathrm{f}}$ & - & - & - \\
\hline & $\uparrow \tau_{\mathrm{y}}$ & - & - & - \\
\hline \multirow[t]{3}{*}{ Multiple influence factors } & $\uparrow \mu_{\mathrm{p}}$ & - & - & - \\
\hline & $\uparrow \Delta \mathrm{p}$ & + & + & + \\
\hline & $\uparrow \mathrm{w}_{0}$ & + & + & + \\
\hline
\end{tabular}

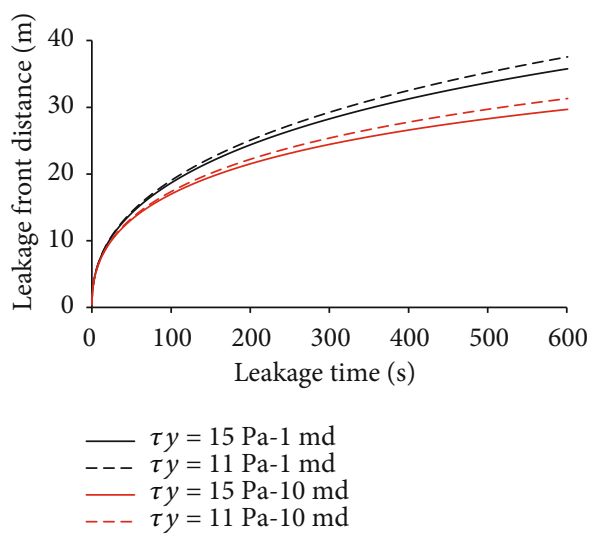

FIGURE 13: Leakage front distance under different formation permeability and yield stress.

a smaller leakage front distance. Although there is little difference in the leakage rate and leakage volume under different formation permeabilities, they have different physical meanings. With an increase in formation permeability $\kappa$, the leakage front distance decreases, which means that the leakage volume $V_{F}(t)$ decreases and the leak-off volume $V_{L}$ $(t)$ increases. In addition, as shown in Eq. (38), with the

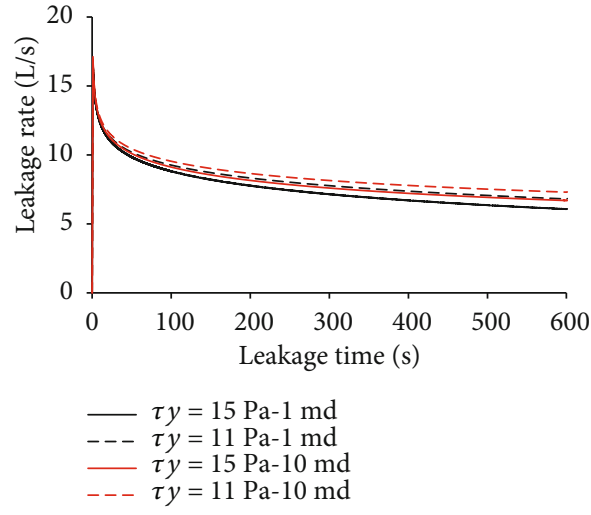

FIGURE 14: Leakage rate under different formation permeability and yield stress.

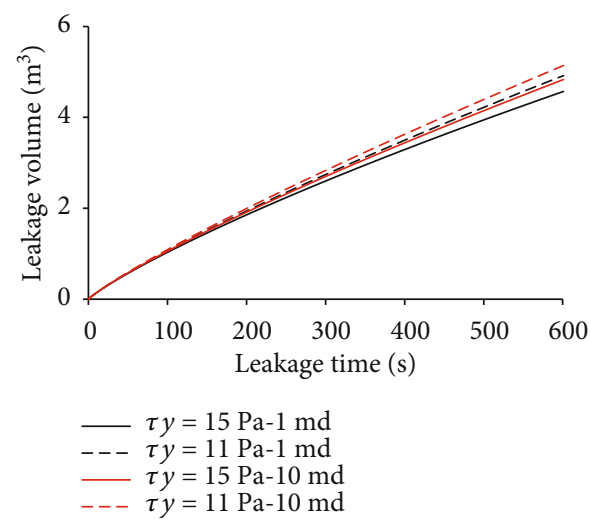

FIgURE 15: Leakage volume under different formation permeability and yield stress.

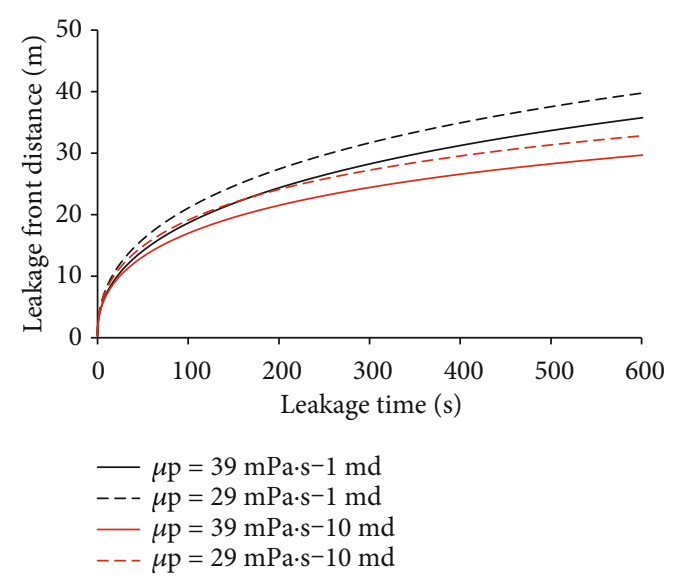

FIGURE 16: Leakage front distance under different formation permeability and plastic viscosity.

increase of $r_{f}$, the effect of $\kappa$ on the leakage rate is evident. Moreover, the lower formation permeability produces a higher leakage invasion speed, which increases the difficulty of solid plugging [26].

5.2. Analysis of Multiple Influence Factors. To analyze the influence of multiple influence factors under different 


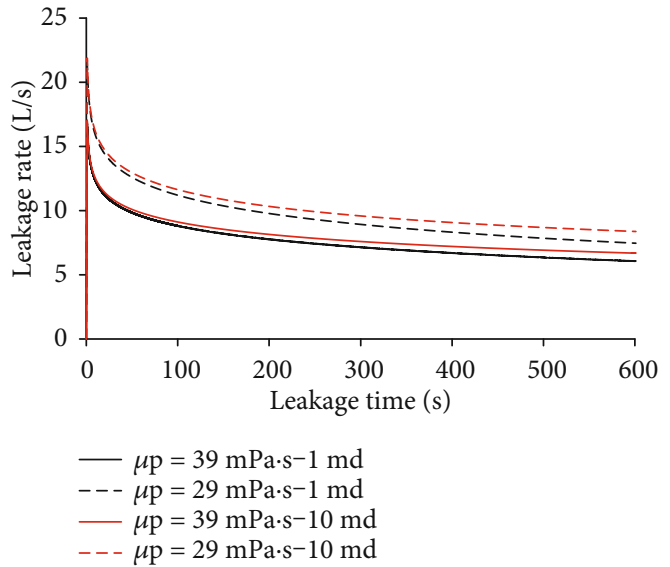

FIGURE 17: Leakage rate under different formation permeability and plastic viscosity.

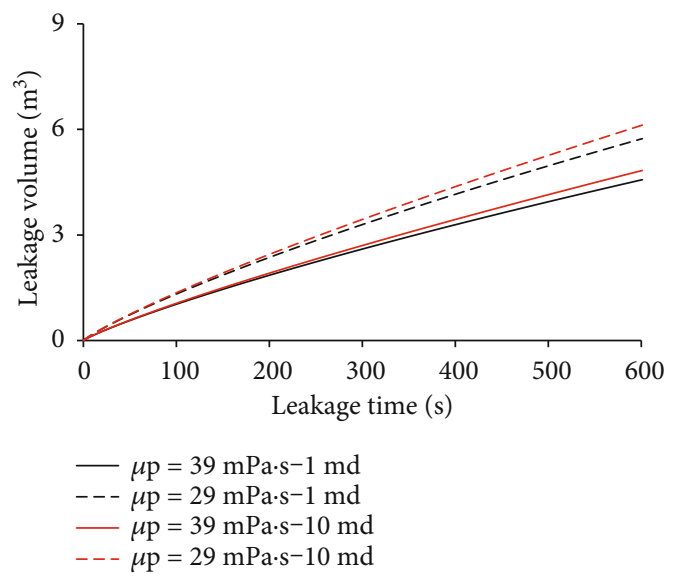

FIGURE 18: Leakage volume under different formation permeability and plastic viscosity.

formation permeabilities, fixing the formation permeability $\kappa$ and setting $\kappa=1$ and $10 \mathrm{md}$ can allow a comparative analysis of the leakage front distance, leakage rate, and leakage volume under the influence of multiple influence factors.

\section{(1) Fracture normal stiffness}

As shown in Figures 10-12, at any given time, a greater fracture normal stiffness causes a smaller leakage front distance, leakage rate, and leakage volume under the same formation permeability. Based on Table 2, it can be seen that the formation permeability and fracture normal stiffness have the same effect on the leakage front distance, while having the opposite effect on the leakage rate and leakage volume. In other words, the leakage front distance decreases with an increase in the formation permeability and fracture normal stiffness. However, the leakage rate and leakage volume increase with increases in formation permeability and decrease with increasing fracture normal stiffness.

(2) Rheological properties of drilling fluid

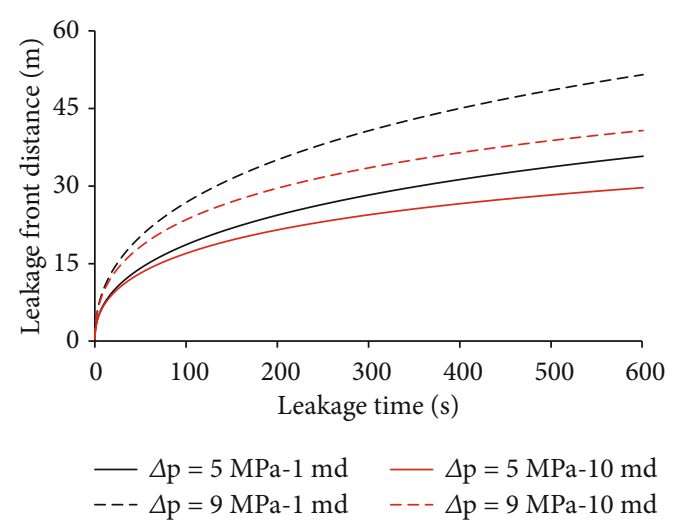

FIgURE 19: Leakage front distance under different formation permeability and well bottom differential pressure.

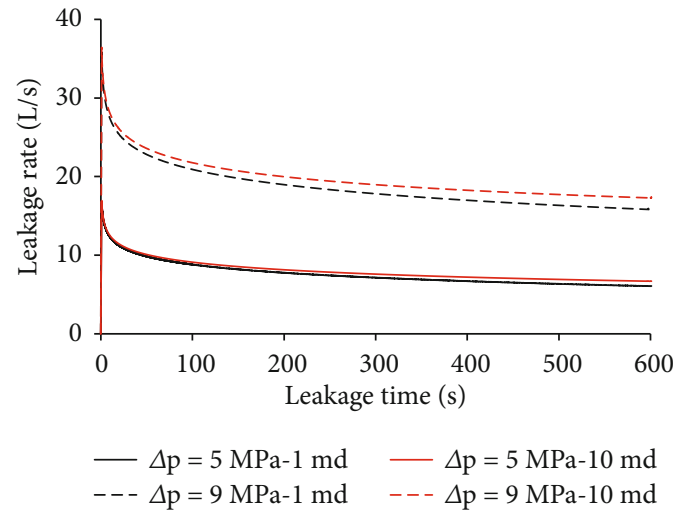

FIGURE 20: Leakage rate under different formation permeability and well bottom differential pressure.

As shown in Figures 13-15, at any given time, a greater normal yield stress causes a smaller leakage front distance, leakage rate, and leakage volume under the same formation permeability. Based on Table 2, it can be seen that the formation permeability and yield stress have the same effect on the leakage front distance while having the opposite effect on the leakage rate and leakage volume. In other words, the leakage front distance decreases with an increase in the formation permeability and yield stress. However, the leakage rate and leakage volume increase with increasing the formation permeability and decrease with increasing yield stress.

As shown in Figures 16-18, at any given time, a greater plastic viscosity causes a smaller leakage front distance, leakage rate, and leakage volume under the same formation permeability. Based on Table 2, it can be seen that the formation permeability and plastic viscosity have the same effect on the leakage front distance while having the opposite effect on the leakage rate and leakage volume. In other words, the leakage front distance decreases with an increase in the formation permeability and plastic viscosity. However, the leakage rate and leakage volume increase with increasing formation permeability and decrease with increasing plastic viscosity.

(3) Well bottom differential pressure 


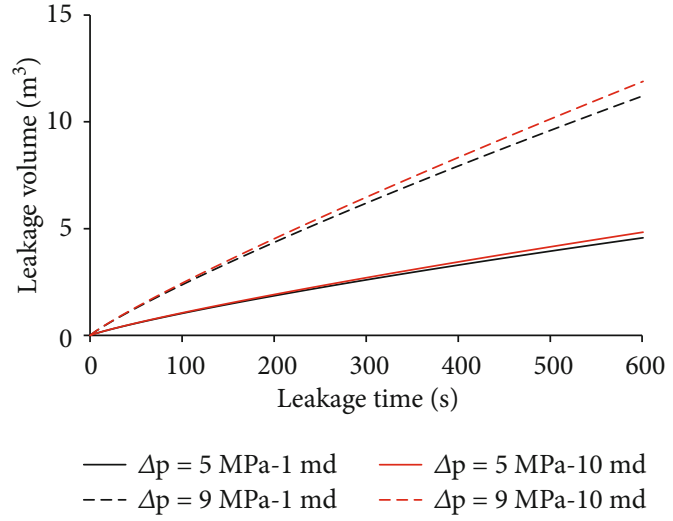

FIGURE 21: Leakage volume under different formation permeability and well bottom differential pressure.

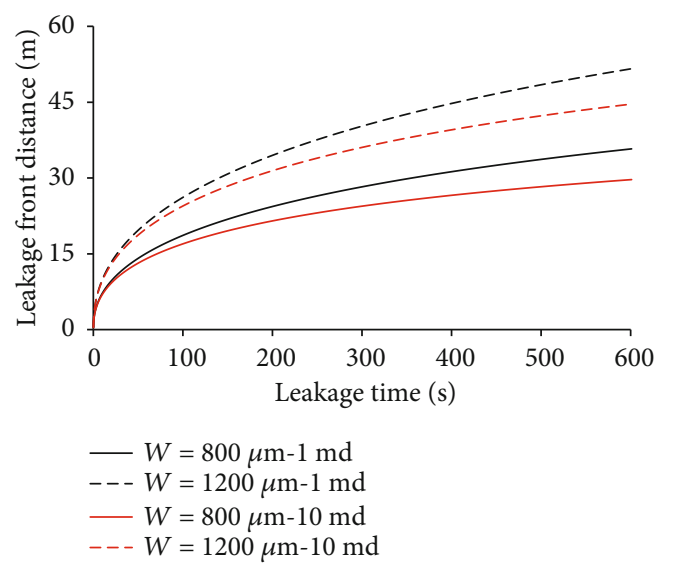

Figure 22: Leakage front distance under different formation permeability and initial width of natural fracture.

As shown in Figures 19-21, at any given time, a greater well bottom differential pressure causes a greater leakage front distance, leakage rate, and leakage volume under the same formation permeability. Based on Table 2, it can be seen that the formation permeability and well bottom differential pressure have opposite effects on the leakage front distance, while having the same effect on the leakage rate and leakage volume. In other words, the leakage front distance decreases with an increase in the formation permeability and increases with an increasing well bottom differential pressure. However, the leakage rate and leakage volume increase with both an increasing formation permeability and well bottom differential pressure.

(4) Initial width of natural fracture

As shown in Figures 21-24, at any given time, a greater initial width of the natural fracture causes a greater leakage front distance, leakage rate, and leakage volume under the same formation permeability. Based on Table 2, it can be seen that the formation permeability and initial width of the natural fracture have opposite effects on the leakage front distance while having the same effect on the leakage rate and

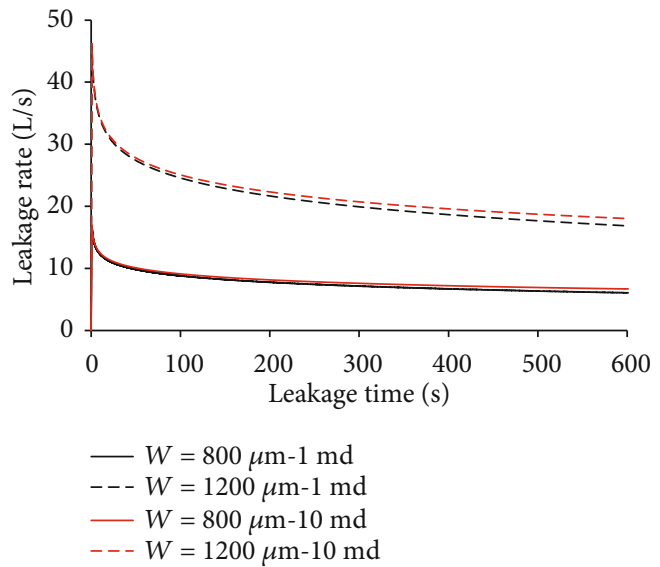

FIGURE 23: Leakage rate under different formation permeability and initial width of natural fracture.

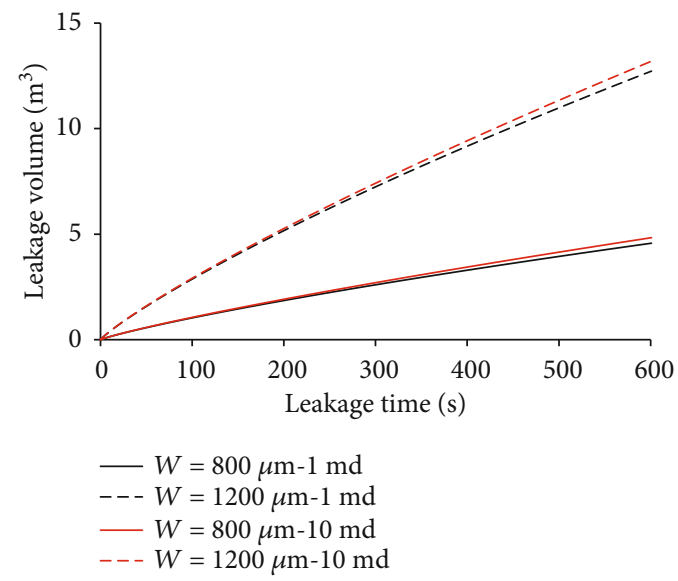

FIGURE 24: Leakage volume under different formation permeability and initial width of natural fracture.

leakage volume. In other words, the leakage front distance decreases with an increase in the formation permeability and increases with an increasing initial width of the natural fracture. However, the leakage rate and leakage volume increase with an increase in both formation permeability and initial width of the natural fracture.

In summary, the leakage front distance decreases with an increase in the formation permeability, fracture normal stiffness, yield stress, and plastic viscosity and increases with an increasing well bottom differential pressure and initial width of natural fracture. The leakage rate and leakage volume increase with increases in formation permeability, well bottom differential pressure, and initial width of the natural fracture; they decrease with increasing fracture normal stiffness, yield stress, and plastic viscosity. As shown in Table 2, the combined impact of an arbitrary combination of two or three sets of influencing factors on leakage front distance, leakage rate, and leakage volume can be obtained by multiplying the single influencing factor. When the impacts have opposite effects, the final result depends on the degree of influence of each factor. 


\section{Conclusions}

(1) The new leakage model clarifies the influence of dualsystem hydromechanical coupling effects between fracture-wall and fracture-inner systems when drilling mud loss occurs in a naturally fractured formation. The model can account for various problems related to the invasion of drilling fluids into the fractures, including predicting the dynamic width of natural fracture and borehole ballooning/breathing phenomena

(2) When drilling mud loss occurs in a naturally fractured formation, the leakage rate increases with an increase in formation permeability, well-bottom differential pressure, and initial width of the natural fracture, while it decreases with an increase in the fracture normal stiffness, yield stress, and plastic viscosity

(3) When drilling mud loss occurs in a naturally fractured formation, at any given time, a greater formation permeability causes a larger leakage rate and leakage volume, whereas a smaller leakage front distance.

\section{Data Availability}

The data used to support the findings of this study are all included within the article.

\section{Conflicts of Interest}

The authors declare that they have no conflicts of interest.

\section{Authors' Contributions}

Hao Peng did the conceptualization; Qian Li did the data curation; JiaJia Gao did the formal analysis; Qian Li did the funding acquisition; $\mathrm{Hu}$ Yin and Jun Wang did the investigation; Hao Peng did the methodology; Qian Li did the supervision; Hu Yin and Jun Wang did the validation; Hao Peng wrote the original draft; Qian Li wrote the review and editing.

\section{Acknowledgments}

National Key Research and Development Project (2019YFA0708302) and the National Natural Science Foundation of China (51804269) funded the project.

\section{References}

[1] C. Ivan, J. Bruton, and B. Bloys, "Lost circulation can be managed better than ever: drilling and completion," World Oil, vol. 224, no. 6, pp. 35-41, 2003.

[2] F. E. Dupriest, "Fracture closure stress (FCS) and lost returns practices," in the SPE/IADC Drilling Conference, pp. 1-12, Amsterdam, Netherlands, February 2005.

[3] C. G. Dyke, B. Wu, and D. Milton-Tayler, "Advances in characterising natural fracture permeability from mud log data," SPE Formation Evaluation, vol. 10, no. 3, pp. 160-166, 2013.
[4] F. Bertuzzi, F. Sanfilippo, M. Brignoli, and G. Parravicini, "Characterization of flow within natural fractures: numerical simulations and field applications," in the SPE/ISRM Eurock 98, pp. 337-345, Trondheim, Norway, July 1998.

[5] G. Beda and C. Carugo, "Use of mud microloss analysis while drilling to improve the formation evaluation in fractured reservoir," in SPE Annual Technical Conference and Exhibition, pp. 1-13, New Orleans, Louisiana, October 2001.

[6] Y. Feng and K. E. Gray, "Modeling lost circulation through drilling-induced fractures," SPE Journal, vol. 23, no. 1, pp. 205-223, 2018.

[7] Y. Feng, J. F. Jones, and K. E. Gray, "A review on fractureinitiation and -propagation pressures for lost circulation and wellbore strengthening," SPE Drilling \& Completion, vol. 31, no. 2, pp. 134-144, 2016.

[8] Y. Feng and K. E. Gray, "Review of fundamental studies on lost circulation and wellbore strengthening," Journal of Petroleum Science and Engineering, vol. 152, pp. 511-522, 2017.

[9] F. Sanfillippo, M. Brignoli, F. J. Santarelli, and C. Bezzola, "Characterization of conductive fractures while drilling," in SPE European Formation Damage Conference, pp. 319-328, Hague, The Netherlands, June 1997.

[10] R. Majidi, S. Z. Miska, M. Yu, and L. G. Thompson, "Fracture ballooning in naturally fractured formations: mechanism and controlling factors," in 2008 SPE Annual Technical Conference and Exhibition, pp. 1-9, Denver, Colorado, USA, September 2008.

[11] O. Lietard, T. Unwin, D. Guillot, and M. Hodder, "Fracture width LWD and drilling mud/LCM selection guidelines in naturally fractured reservoirs," in the European Petroleum Conference, pp. 181-192, Mila, Italy, October 1996.

[12] R. Majidi, S. Miska, L. G. Thompson, M. Yu, and J. Zhang, "Quantitative analysis of mud losses in naturally fractured reservoirs: the effect of rheology," SPE Drilling \& Completion, vol. 25, no. 4, pp. 509-517, 2013.

[13] M. P. Shahri and M. Mehrabi, "A new approach in modeling of fracture ballooning in naturally fractured reservoirs," in the SPE Kuwait International Petroleum Conference and Exhibition, pp. 1-20, Kuwait City, Kuwait, December 2012.

[14] M. Ozdemirtas, T. Babadagli, and E. Kuru, "Effects of fractal fracture surface roughness on borehole ballooning," Vadose Zone Journal, vol. 8, no. 1, pp. 250-257, 2009.

[15] M. Ozdemirtas, E. Kuru, and T. Babadagli, "Experimental investigation of borehole ballooning due to flow of nonNewtonian fluids into fractured rocks," International Journal of Rock Mechanics and Mining Sciences, vol. 47, no. 7, pp. 1200-1206, 2010.

[16] A. Lavrov and J. Tronvoll, "Mechanics of borehole ballooning in naturally-fractured formations," in the 14th SPE East Oil \& Gas Show and Conference, pp. 1-7, Bahrain International Exhibition Centre, Bahrain, March 2005.

[17] A. Lavrov and J. Tronvoll, "Modeling mud loss in fractured formations," in the Abu Dhabi International Petroleum Exhibition and Conference, pp. 1-10, Abu Dhabi, U.A.E, October 2004.

[18] A. Lavrov and J. Tronvoll, "Mud loss into a single fracture during drilling of petroleum wells: modeling approach," in Proceedings of the 6th International Conference ICADD-6, pp. 189-198, Trondheim, Norway, October 2003.

[19] V. Dokhani, Y. Ma, Z. Li, T. Geng, and M. Yu, "Transient Effects of Leak-off and Fracture Ballooning on Mud Loss in 
Naturally Fractured Formations," in 53rd US Rock Mechanics/Geomechanics Symposium, pp. 1-9, New York, NY, USA, 26 June 2019.

[20] M. Bychina, G. M. Thomas, R. Khandelwal, and R. Samuel, “A robust model to estimate the mud loss into naturally fractured formations," in the SPE Annual Technical Conference and Exhibition, pp. 1-12, San Antonio, USA, October 2017.

[21] O. Razavi, H. P. Lee, J. E. Olson, and R. A. Schultz, "Drilling mud loss in naturally fractured reservoirs: theoretical modelling and field data analysis," in the SPE Annual Technical Conference and Exhibition, pp. 1-26, San Antonio, USA, October 2017.

[22] M. A. Biot, "Theory of elasticity and consolidation for a porous anisotropic solid," Journal of Applied Physics, vol. 26, no. 2, pp. 182-185, 1955.

[23] R. O. Roko and J. Daemen, "Analysis of deformation of joint asperities and mechanical implications," in Proceeding of the 29th U.S. Symposlum, pp. 127-134, USA, January 1988.

[24] S. E. Laubach, J. E. Olson, and J. F. Gale, "Are open fractures necessarily aligned with maximum horizontal stress?," Earth and Planetary Science Letters, vol. 222, no. 1, pp. 191-195, 2004.

[25] J. F. Gale, R. M. Reed, and J. Holder, "Natural fractures in the Barnett shale and their importance for hydraulic fracture treatments," AAPG Bulletin, vol. 91, no. 4, pp. 603-622, 2007.

[26] O. Razavi, A. K. Vajargah, E. van Oort, M. Aldin, and R. Patterson, "How to effectively strengthen wellbores in narrow drilling margin wells: an experimental investigation," in the SPE Annual Technical Conference and Exhibition, pp. 124, Houston, USA, September 2015. 